\title{
Prevention of cross infection during outpatient spirometry
}

Jo Marchant, Andrew Bush

\begin{abstract}
Lung function apparatus may be a source of cross infection in patients with cystic fibrosis and may be prevented using a 'bag in bottle' system. As this system has never been validated in children the flow volume loops performed using a Vitalograph Compact in the usual way were compared with results obtained blowing into the bag and bottle system, in random order, in 20 children with asthma (age 8-15 years). Three reproducible flow volume loops were recorded for each apparatus. There was no order effect. Mean (SE) results for forced expiratory volume in one second, forced vital capacity (FVC), peak expiratory flow rate, and maximum expiratory flow at between $75 \%$ and $25 \%$ of FVC showed respectively that the bag in bottle results were significantly greater than those obtained blowing directly into the spirometer by 90 (17) $\mathrm{ml}, 12 \cdot 7(5 \cdot 1) \mathrm{l} / \mathrm{min}$, 130 (60) $\mathrm{ml} / \mathrm{min}$. Although statistically significant, these differences are within the previously described coefficients of variation for children with cystic fibrosis and are of doubtful clinical relevance. It is concluded that the bag in bottle system does not introduce any important systematic error. It potentially offers absolute protection from cross infection. (Arch Dis Child 1995; 72: 156-158)
\end{abstract}

Keywords: spirometry, cross infection, cystic fibrosis, lung function.

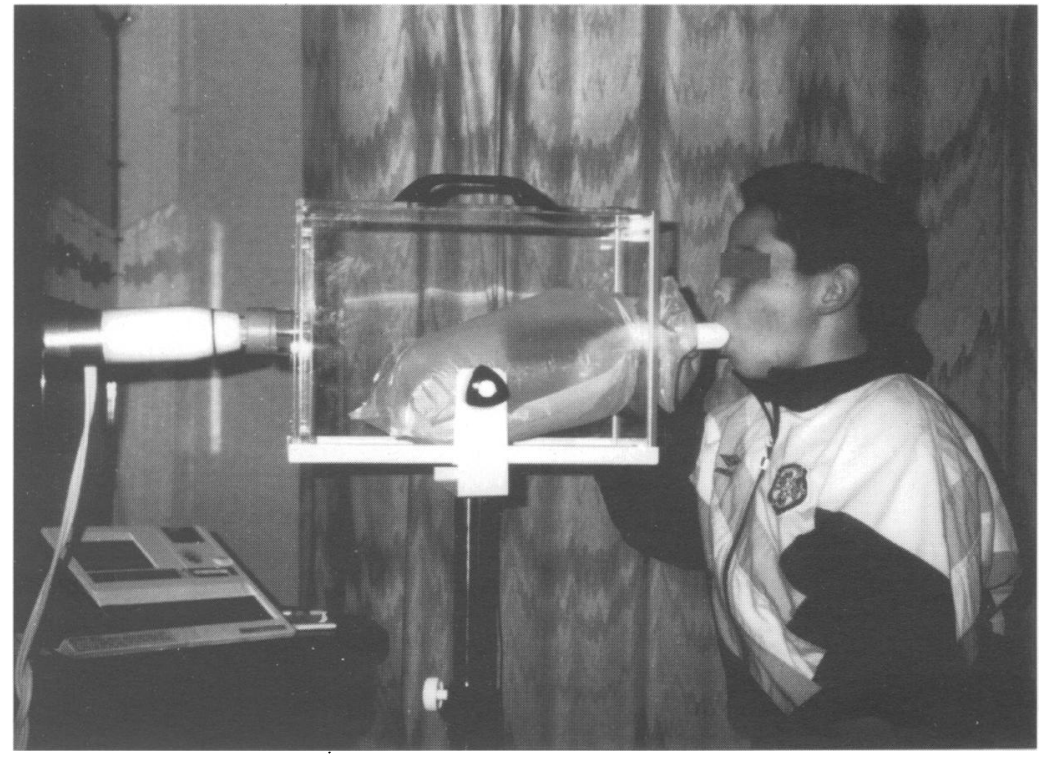

Figure 1 The apparatus in use. The child blows into the plastic bag, which is confined within the rigid Perspex box. The box is connected to the Vitalograph Compact.
There are growing concerns about cross infection particularly with Pseudomonas cepacia, but also with methicillin resistant Staphylococcus aureus between patients with cystic fibrosis. ${ }^{1}$ Contamination of lung function apparatus by $P$ cepacia has been described, ${ }^{1}$ and may be one way whereby this pathogen is transmitted from one patient to another. ${ }^{12}$ We routinely perform flow volume curves using the Vitalograph Compact on all patients over 5 years of age when they attend our cystic fibrosis clinic. To get optimum readings it is vital that the patient breathes out as hard and as long as possible into the mouthpiece. It is often difficult for children to coordinate their breathing enough to remove the mouthpiece before breathing in again, and therefore some inspire from the body of the spirometer into which other cystic fibrosis patients will have just blown.

Our previous work has shown that the risk of cross contamination through lung function apparatus is small. ${ }^{3}$ However, we felt that with the anxiety over cross infection with $P$ cepacia ${ }^{4}$ it was preferable completely to eliminate any risk. A disposable 'bag in bottle' spirometry system has been in use in our hospital lung function department for five years ${ }^{6}$ but never validated in children nor used in a routine outpatient setting. The purpose of this study was to determine whether the use of this system significantly affects the results of spirometry in children.

\section{Patients and methods}

STUDY 1

Calibrations were performed using a three litre syringe. The spirometer used was the Vitalograph Compact in use routinely in our clinic. Ten calibrations were performed placing the syringe in the flow head in the usual way, and 10 using the bag in bottle system.

\section{STUDY 2}

We recruited 20 children (five girls) from the paediatric asthma clinic; their age range was 8-15 years. Asthma had been diagnosed on standard criteria. ${ }^{7}$ Informed consent was given by all children and their parents. All children had performed flow volume loops many times previously. The spirometer was calibrated with a three litre syringe before and after each child had been studied. The bag in bottle system was supplied by $\mathbf{P}$ K Morgan (Chatham, Kent). A disposable mouthpiece was attached to a plastic connection that 

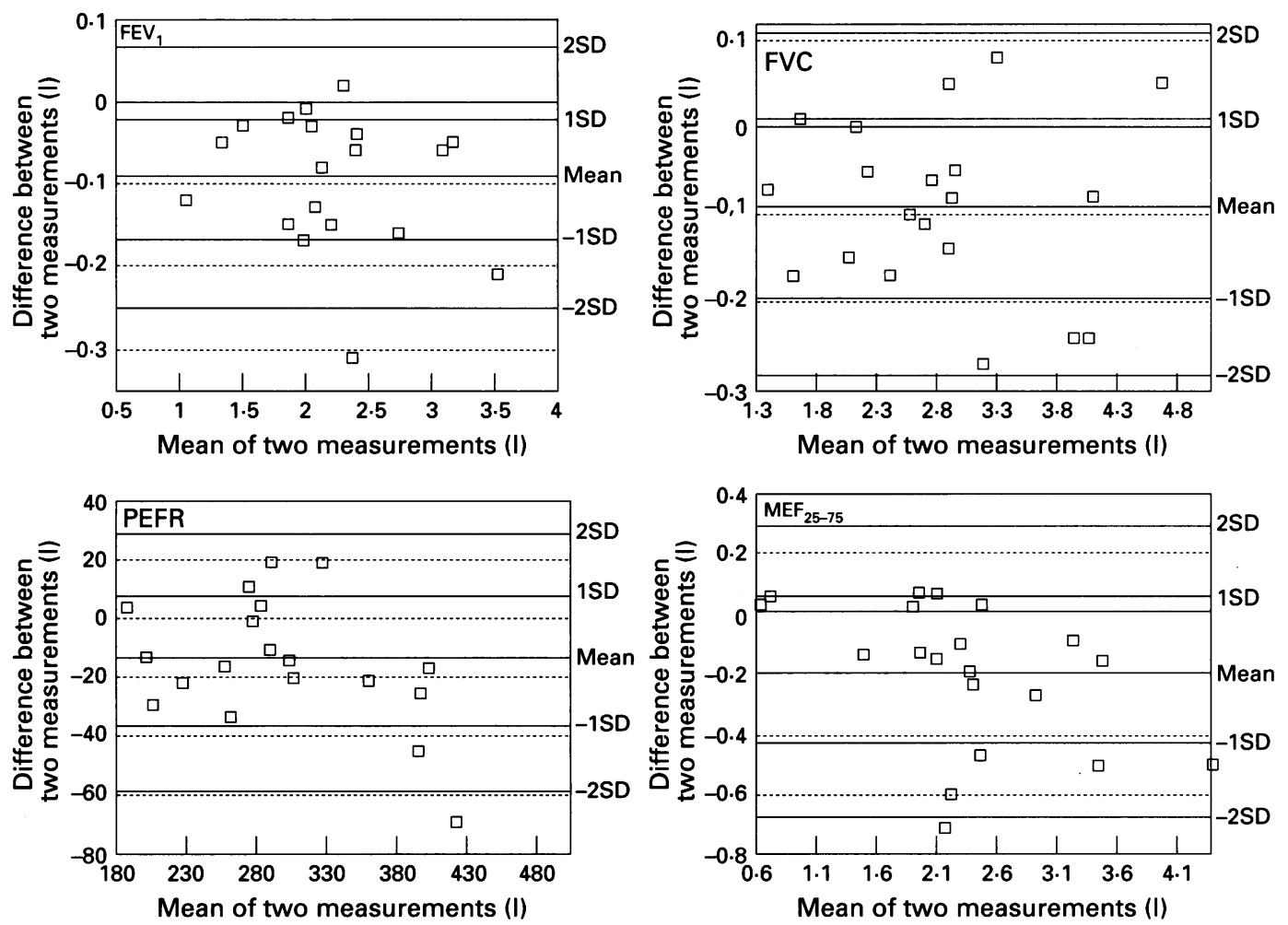

Figure 2 Comparison of lung function variables measured by blowing directly into the Vitalograph Compact and using the bag and bottle system. The horizontal axis is the mean of the direct and bag in bottle measurements; the vertical axis is the difference between the two measurements; a minus sign indicates an overestimate by the bag in bottle system.

entered the Perspex box, creating an airtight seal. A disposable plastic bag was mounted onto the other end of this connector into which the patient breathes. The flowhead of the Vitalograph Compact was attached also with an airtight seal onto the other end of the Perspex box (fig 1). The mouthpiece and bag were discarded between patients and the plastic connector sterilised using Milton sterilising tablets. The children were randomly divided into two groups of 10 . Each group performed three blocks of three reproducible flow volume loops. Group one performed a block of spirometer only, followed by the bag in bottle block, followed by a spirometer only block. Group two performed bag in bottle, followed by spirometer only, followed by bag in bottle. For each block of three tests, the manoeuvre with the best forced expiratory volume in one second $\left(\mathrm{FEV}_{1}\right)$ and associated measurements was selected for analysis.

Data were analysed using the Minitab package. Analysis of variance was used to detect any order effects, and paired $t$ tests for comparisons between measurements. Bland and Altman plots were used for visual displays of comparison. Results were considered significant at the $\mathrm{p}<0.05$ level.

\section{Results}

STUDY 1

There was no significant difference between the direct and bag in bottle calibrations (mean (SE) direct $2.95(0.01) 1 v$ bag in bottle 2.95 $(0.01) \mathrm{l} ; \mathrm{p}>0.05)$, although both under-read the true injected volume of three litres.
STUDY 2

The mean (range) baseline lung function measurements for the children studied are $\mathrm{FEV}_{1} 2 \cdot 14(0 \cdot 99-3 \cdot 42)$ 1; forced vital capacity (FVC) $2.77(1.51-4.60) \mathrm{l}$; and peak expiratory flow rate (PEFR) 308 (188-508) $1 / \mathrm{min}$. Analysis of variance showed that there was no significant order effect between the different blocks of measurements, so the group data were amalgamated, and the second and third blocks compared using paired $t$ tests. The results for $\mathrm{FEV}_{1}$, FVC, PEFR, and maximum expiratory flow between $75 \%$ and $25 \%$ FVC $\left(\mathrm{MEF}_{25-75}\right)$ are shown graphically in fig 2 . There is a small but statistically significant overestimate by the bag in bottle system for all measurements (mean (SE): $\mathrm{FEV}_{1} 90$ (17) ml, FVC 90 (22) $\mathrm{ml}$, PEFR 12.7 (5.1) $1 / \mathrm{min}$, $\mathrm{MEF}_{25-75} 130(60) \mathrm{ml} / \mathrm{min} ; \mathrm{p}<0.05$ in all cases).

\section{Discussion}

This study was designed to determine whether the use of the bag in bottle system introduced any systematic error in spirometry when used in children. There were small but statistically significant differences in spirometric indices measured with the bag in bottle system. However, our first study using a calibration syringe showed no significant difference between the two systems. We are not able to account for this difference, because the effect of any leak in the bag in bottle system (which we were at pains to eliminate) would have been an underestimate of the results. We can only speculate that the use of the box may have affected posture or some other factor in such a 
way that there were minor improvements in performance. The absolute values of the overestimates were however small (of the order of $5 \%$ ), which is well within the coefficient of variation of both normals and children with cystic fibrosis, ${ }^{89}$ and is unlikely to introduce significant errors into clinical practice.

The cost of introducing this system is $\$ 575$ for the apparatus with the plastic pieces holding the mouthpiece costing a further $£ 64$, and $£ 2$ for 50 disposable bags. By comparison, filtered mouthpieces (Vitalograph) cost $£ 24.80$ for 200. Thus the use of the bag in bottle system saves $£ 8.80$ per 100 examinations, at a cost of an initial outlay of $£ 639$. We know of no published research on the protective effects (if any) of these filters. The alternative is to take no precautions at all, and ask children not to breathe in from the apparatus. In our experience, some children inspire despite the most careful instructions. The clinical importance of this is not known, but even a small risk should not be taken unnecessarily.

Subsequent to performing this study, we have introduced the bag in bottle system into our cystic fibrosis clinic. We have performed more than 500 tests using this equipment over the past 12 months. Delays are minimal, and no patient has refused to use it. Such infection precautions are probably not necessary in an asthma clinic if the risk of methicillin resistant $S$ aureus is low. However, in a cystic fibrosis clinic, although the risk of cross infection is probably very low, we suggest that this simple technique should become routine in view of the potentially catastrophic consequences of $P$ cepacia and methicillin resistant $S$ aureus.

1 Govan JRW, Brown PH, Maddison J, et al. Evidence of transmission of Pseudomonas cepacia by social contact in transmission of Pseudomonas cepacia

2 Nelson JW, Doherty CJ, Brown PH, Greening AP, Kaufman ME, Govan JRW. Pseudomonas cepacia in inpatients with cystic fibrosis. Lancet 1991; 338: 1525 .

3 Marchant JL, Little SA, Bush A. Flow volume curves in children with cystic fibrosis - a possible risk of cross-infection? Respir Med 1994; 88: 235-6.

4 Walters S, Smith EG. Pseudomonas cepacia in cystic fibrosis: transmissibility and its implications. Lancet 1993; 342: 3-4.

5 Stableforth DE, Smith DL. Pseudomonas cepacia in cystic fibrosis. Thorax 1994; 49: 629-30.

6 Denison DM, Cramer DS, Hanson PJV. Lung function testing and AIDS. Respir Med 1989; 83: 133-8.

7 Warner JO, Gotz M, Landau LI, et al. Management of asthma: a consensus statement. Arch Dis Child 1989; 64: 1065-79.

8 Nickerson BG, Lemen RJ, Gerdes CB, Wegmann MJ, Robertson G. Within-subject variability and per cent Robertson G. Within-subject variability and per cent
change for significance of spirometry in normal subjects and in patients with cystic fibrosis. Am Rev Respir Dis 1980;

9 Redding GJ, Restuccia R, Cotton EK, Brooks JG. Serial changes in pulmonary functions in children hospitalised for cystic fibrosis. Am Rev Respir Dis 1982; 126: 31-5. 